another taken at the Lick Observatory in I9I3; also in a photograph taken at Allegheny at Mr. Hubble's request. The most striking change was what at first appeared to be a transverse shift of a bright patch just north of the nucleus, but further examination suggested that this was more probably due to the sudden appearance of a mass of bright nebulosity. There are several other differences between the photographs which appear to be due to real changes in the nebula. In particular, a small mass a little southeast of the nucleus exhibits a decided irregular movement, having moved in towards the nucleus when the above-mentioned new mass appeared. This small mass moved not less than $0.5^{\prime \prime}$ per vear between 1008 and 1913 , and it seems likely to have a measurable parallax.

Rotation of the entire nebula would not account for the variations observed, but some of the changes may be explained by local brightening and fading of stationary matter. Actual motion of portions of nebulosity relative to the nebula as a whole, however, is regarded by $\mathrm{Mr}$. Hubble as the probable explanation of most of the changes observed. The spectrum of the nebula has been found to be. continuous.

The Structure of the Re' Lithium Line.-The complex structure of the red line of lithium, $\lambda 6708$, has been further investigated by Dr. A. S. King at the Passadena Laboratory (Astrophysical Journal, vol. xliv., p. $\mathrm{r}_{72}$ ). It is shown that the line may appear with two distinct sets of components, either as an unsymmetrical doublet, or as a triplet of variable separation. In a third stage the side components of the triplet change into an ordinary reversal within which the central component can still be seen. All three conditions of the line may be produced either in the arc or electric furnace, and the controlling agency appears to be the amount of vapour in the source. The variable interval of the components suggests an electrical resolution, which would most likely be due to the action of interatomic fields. The observations have proved that the line at 6708 which commonly appears in calcium spectra is due to lithium impurity. Also, it may now be considered certain that the strong line appearing at this position in the spectra of sunspots should be attributed to lithium. It is remarkable that this should be the only direct proof of the presence of lithium in the sun, there being no representatives of this element in the Fraunhofer spectrum.

\section{PLANTATION RUBBER.}

$\mathrm{T}$ HE Trade Supplement of the Times for December is devoted almost entirely to plantation rubber. The editor has drawn upon some of the best authorities in the plantation world for his contributions, and without exaggeration has achieved a pronounced success. The articles deal with the development of the plantation rubber industry throughout the Middle East, the physical, biological, and chemical problems involved in the preparation of the raw material, and the importance of the supplies to the manufacturing industry in this and every other country.

The large number of contributors has resulted in repetition of the same facts, but this was scarcely avoidable in such an issue. Much of the information has already been disseminated in text-books and technical journals, but the matter has been rendered in this supplement in a form which will appeal to all interested in the industry either financially or technically.

In one of the most important articles Prof. J. Bretland Farmer outlines the risks of tropical agriculture, the efforts which have been made by Government and private individuals, and the need for still greater pre- caution and the placing of the industry on a better scientific foundation. It is already known that the Imperial College of Science has sent a number of scientific officers to the Middle East, and we know from personal contact with them that they have felt the necessity of periodically spending a part of their time in first-rate laboratories in Europe or America. It is impossible for the scientific. officers in charge of plantations in the Middle East to be conversant with all the advances made in plant sanitation, biological problems, and testing apparatus of value to the plantation industry

A brief survey of the article on "Pests and Diseases," by Mr. J. Mitchell, satisfies one that there is every reason why the many diseases affecting the roots, bark, stems, and fruits of Hevea brasiliensis should be carefully watched. The necessity for independent scientific officers to be put in charge of such work is quite apparent even to the ordinary investor, who has but little knowledge of mycological and entomological problems

With regard to the physical and chemical researches in the laboratories of the manufacturers, some very useful information is contributed by Mr. W. A. Williams, Dr. Joseph Torrey, and Dr. Philip Schidrowitz. There is a great lack of uniformity in cultivated rubber, which materially affects processes of manufacture and the finished article. It is suggested that the difficulties consequent on variation of plantation rubber can be reduced by standardisation of methods of preparation on the estate and by closer co-operation with manufacturers in this country. The lack of cooperation between plantation growers and manufacturers is emphasised by Mr. Alexander Johnston.

A review of this supplement cannot be completed without reference to the very strong article by Mr. E. Stevenson, chairman of the Rubber Trade Association of London. Mr. Stevenson points out the absolute need of organisation, and shows that the growers themselves are very largely responsible for the competitive system which they have set up. Organisation is apparently as necessary among producers, manufacturers, and dealers in raw rubber as it is on the plantations, and the supplement before us will serve a good purpose if it results in any definite advances being made in this direction.

H. W.

\section{MARINE ISOPODA FROM THE NORTH ATLANTIC. ${ }^{1}$}

THE papers before us form two of the valuable series of reports now being issued by the Danish Government, through the Zoological Museum at Copenhagen, on the results of the exploration of the deep sea in the neighbourhood of Greenland, Icelant and the Faröes. They constitute a monograph of th Isopoda and Tanaidacea of that region, and their importance may be judged from the fact that, whereas previously only fifty-three species of Isopoda were known from the area surveyed, Dr. Hansen records 242 species, of which 125 are described for the first time, and establishes eighteen new genera. This satisfactory result is due to the methods of collecting introduced by the author during the expedition. The mud brought up in the trawl and dredge was carefully sifted through fine bolting silk, and the results of the sifting preserved for future examination. In this way hundreds of small animals, which could not have been collected by any other means, were discovered. This method may be recommended to naturalists in charge of future expeditions for the ex-

1 "The Danish Ingolf Expedition." Vol. iii., No. 3, "Crustacea Malacostraca," II. By H. J. Hansen. Pp. I45+ 12 plates." (rgr3.)

"The Danish Ingolf-Expedition." Vol. iit., No. 5, "Crustacea Mala costraca," III, Pp. $262+16$ p'ates (Copenhagen:' Printed by $B$ anco

NO. 2459, VOL. 98] 